\title{
COMPROMISSO DE AJUSTAMENTO DE CONDUTA E IMPLEMENTAÇÃO DE POLÍTICAS PÚBLICAS
}

\author{
Thadeu Augimeri de Goes Lima ${ }^{1}$
}

LIMA, T. A. de G. Compromisso de ajustamento de conduta e implementação de políticas públicas. Rev. Ciênc. Juríd. Soc. UNIPAR. Umuarama. v. 17, n. 2, p. 205-226, jul./dez. 2014

RESUMO: O artigo estuda a eficácia do compromisso de ajustamento de conduta como instrumento para obter a implementação de políticas públicas e a efetivação de direitos fundamentais sociais. Vale-se dos métodos hipotético-dedutivo, dialético e histórico-evolutivo e parte de marcos teóricos inseridos na concepção neoconstitucionalista. Inicia pela abordagem do neoconstitucionalismo e de sua manifestação no Brasil, constatando que os direitos fundamentais sociais previstos na Constituição Federal de 1988 sofrem uma crise de efetivação decorrente da ausência de políticas públicas sociais capazes de implementá-los. Continua com a análise do compromisso de ajustamento de conduta no Direito brasileiro, fixando seus antecedentes, sua natureza jurídica e conceito e suas características essenciais, especialmente os órgãos autorizados a celebrá-lo, seu objeto, sua forma e seus efeitos. Na sequência, ressalta as vantagens da prevenção e da resolução extrajudicial dos conflitos transindividuais possibilitadas pelo compromisso de ajustamento de conduta, notadamente as maiores celeridade e efetividade e o afastamento das críticas dirigidas à expansão da jurisdição constitucional e à judicialização da política. A conclusão confirma a hipótese desenvolvida na Introdução, verificando a grande relevância do instituto para a implementação de políticas públicas e a concretização dos direitos fundamentais sociais. O valor e a originalidade do trabalho estão principalmente no cotejo analítico do modelo consensual com a tradicional solução adjudicada estatal e no destaque às vantagens do primeiro sobre a última.

PALAVRAS-CHAVE: Compromisso de ajustamento de conduta; Políticas públicas; Direitos fundamentais sociais.

DOI: https://doi.org/10.25110/rcjs.v17i2.2014.5401

${ }^{1}$ Mestre em Ciência Jurídica pela Universidade Estadual do Norte do Paraná (UENP). Especialista em Direito e Processo Penal pela Universidade Estadual de Londrina (UEL). Coordenador e professor do Curso de Pós-Graduação (nível de especialização) em "Ministério Público e Estado Democrático de Direito" da Fundação Escola do Ministério Público do Estado do Paraná (FEMPAR), unidade de Londrina. Promotor de Justiça de Entrância Final no Estado do Paraná, titular na Comarca da Região Metropolitana de Londrina. 


\section{INTRODUÇÃO}

Passados mais de vinte e cinco anos desde a promulgação de nossa atual Constituição Federal, em 1988, o déficit de cumprimento de suas disposições se mostra assombroso.

Com efeito, muitos dos direitos fundamentais sociais previstos em seu texto ainda se encontram carentes de efetivação, especialmente em razão da ausência de políticas públicas imprescindíveis para proporcionar a fruição pelos respectivos destinatários.

Sobreleva, destarte, diante desse infeliz quadro, a importância do estudo dos mecanismos institucionais e instrumentais disponibilizados pelo ordenamento jurídico para concretizar as descumpridas promessas trazidas no art. $3^{\circ}$. da Lei Maior, de construir uma sociedade livre, justa e solidária (inciso I); garantir o desenvolvimento nacional (inciso II); erradicar a pobreza e a marginalização e reduzir as desigualdades sociais e regionais (inciso III); e promover o bem de todos, sem preconceitos de origem, raça, sexo, cor, idade e quaisquer outras formas de discriminação (inciso IV).

No contexto ora descrito, merece grande atenção o compromisso de ajustamento de conduta, ferramenta de prevenção e resolução extrajudicial de conflitos envolvendo interesses transindividuais que, bem compreendido e manejado, pode contribuir de maneira decisiva para remediar as omissões constatadas.

Eis, resumidamente, o objetivo deste artigo: analisar a eficácia do compromisso de ajustamento de conduta como instrumento para obter a implementação de políticas públicas e a efetivação de direitos fundamentais sociais.

São preferencialmente empregados, na consecução da tarefa proposta, os métodos hipotético-dedutivo, dialético e histórico-evolutivo.

Com efeito, a hipótese ora levantada, posicionando-se no sentido da inequívoca utilidade do instituto, é submetida a falseamento mediante o cotejo das características do mesmo com o modelo clássico de judicialização, parâmetro adequado de comparação para os fins pretendidos.

Antes, porém, não pode ser olvidado o exame de suas origens históricas e de seu desenvolvimento ao longo do tempo, bem como devem ser confrontadas e criticamente avaliadas as diferentes opiniões de respeitados juristas que se debruçaram sobre o tema, procurando organizá-las em uma síntese superadora de suas possíveis contradições.

Outrossim, o presente estudo parte de referenciais teóricos que se inserem na concepção doutrinária conhecida por neoconstitucionalismo, notadamente as correntes que preconizam a força normativa dos princípios e regras insculpidos na Constituição e a irradiação de seus efeitos sobre todo o Direito 
infraconstitucional.

Na primeira seção do trabalho, são correlacionados o neoconstitucionalismo, a previsão de direitos fundamentais sociais nas Constituições contemporâneas e o dever do Estado Democrático de Direito de implementá-los por intermédio de políticas públicas, analisando a realidade brasileira.

Em seguida, na segunda seção, examinam-se as noções basilares sobre o compromisso de ajustamento de conduta.

Na terceira seção do artigo são identificadas as vantagens proporcionadas pelo compromisso de ajustamento de conduta para a implementação de políticas públicas e a efetivação de direitos fundamentais sociais, encerrando-se com a conclusão obtida no trato do assunto.

\section{NEOCONSTITUCIONALISMO, DIREITOS FUNDAMENTAIS SOCIAIS E POLÍTICAS PÚBLICAS: O (DES)CASO BRASILEIRO}

No segundo pós-guerra, sobretudo depois da Declaração Universal dos Direitos Humanos, aprovada pela Assembleia Geral da Organização das Nações Unidas em 10 de dezembro de 1948, verificou-se a emergência de um novo e vigoroso constitucionalismo, de inspiração nitidamente humanista (DELLARI, 2010), que conferiu à Constituição, Lei Maior do Estado, papel de primazia e de direcionamento em relação ao ordenamento jurídico-positivo. Com efeito, deixou ela de ser compreendida como mera "carta de intenções políticas" ou, pejorativamente, singela "folha de papel" dependente dos fatores reais de poder, passando a ser reconhecida como dotada de preponderância, de efetiva força normativa e de irradiação sobre todo o Direito infraconstitucional.

No que tange a seu conteúdo, outrossim, as Constituições, em suas várias manifestações concretas no mundo ocidental, viram-se enriquecidas com a consagração do Estado Democrático de Direito, que se lastreia no valor fundamental da dignidade da pessoa humana e em imperativos axiológicos de moral e justiça.

O Estado Democrático de Direito consubstancia um aprofundamento das fórmulas do Estado de Direito e do Estado de Bem-Estar Social (Welfare State), impondo à ordem jurídica e à atividade estatal um cerne utópico de transformação do status quo, isto é, um caráter prospectivo e emancipador (STRECK, 2002).

As Constituições modernas desempenham relevante função na modificação da realidade, porquanto se notabilizam pela presença de metarregras sobre a produção do Direito, exatamente para vincular os poderes públicos, inclusive com a previsão de mecanismos contramajoritários, no escopo de dirigir a ordem jurídica à concretização dos direitos fundamentais de todos (CAMBI, 2009). 
Essa nova maneira de ver a Constituição, que envolve o indeclinável compromisso de cumprir suas disposições e de realizá-la integralmente na vida cotidiana, perpassa diferentes concepções doutrinárias que, grosso modo, diante da apontada identidade metodológica e teleológica, podem ser agregadas sob o rótulo do neoconstitucionalismo (CAMBI, 2008).

Traço marcante e destacado do Estado Democrático de Direito, herdado do Estado Social, porém intensificado no novel modelo (STRECK, 2002), é a previsão, no texto constitucional, de normas que estabelecem posições jurídicas subjetivas ativas invocáveis por seus titulares no sentido de exigirem do ente público determinadas atuações positivas, de cunho jurídico ou material. Integram o gênero que Ingo Wolfgang Sarlet denomina de direitos a prestações em sentido amplo, e que abrange, como suas espécies, os direitos à proteção, os direitos à participação na organização e procedimento e os direitos a prestações em sentido estrito (SARLET, 2009). Os últimos, também referidos pelo autor como direitos sociais prestacionais, voltam-se, essencialmente, à melhoria das condições de vida e à consecução da igualdade material e da justiça social, garantindo a participação do povo na distribuição pública de bens materiais e imateriais (Id. Ibid.).

A problemática maior dos chamados direitos a prestações em sentido estrito, direitos sociais prestacionais ou, simplesmente, direitos sociais consiste na sua efetividade, quer-se dizer, na sua implementação prática e consequente fruição pelos beneficiários, conforme explana José Eduardo Faria (2004, p. 272273):

Ao contrário dos direitos individuais, civis e políticos e das garantias fundamentais desenvolvidas pelo liberalismo burguês com base no positivismo normativista, cuja eficácia requer apenas que o Estado jamais permita sua violação, os "direitos sociais" não podem simplesmente ser "atribuídos" aos cidadãos. Como não são self-executing nem muito menos fruíveis ou exequíveis individualmente, esses direitos têm sua efetividade dependente de um welfare commitment. Em outras palavras, necessitam de uma ampla e complexa gama de programas governamentais e de políticas públicas dirigidas a segmentos específicos da sociedade; políticas e programas especialmente formulados, implementados e executados com o objetivo de concretizar esses direitos e atender às expectativas por eles geradas com sua positivação. A inexistência dessas políticas e desses programas, é evidente, acaba implicando automaticamente a denegação desses direitos.

Alguns aspectos pragmáticos são decisivos para gerar a crise de efetividade dos direitos fundamentais sociais. Via de regra, as reais condições para o exercício dessas prerrogativas constitucionais precisam ser ainda criadas, e a 
criação delas se mostra economicamente mais custosa, mormente porque cada direito social costuma demandar uma prestação estatal exclusiva, que somente é aproveitada em sua realização, e não na de outros (SILVA, 2010).

Em síntese, os direitos a prestações em sentido estrito dependem inexoravelmente de políticas públicas (CAMBI, 2009), expressão que, em sentido lato, "designa todas as atuações do Estado, cobrindo todas as formas de intervenção do poder público na vida social" (GRAU, 2005, p. 26). Para uma conotação mais restrita e adequada ao objeto do presente trabalho, faz-se pertinente o acréscimo do adjetivo sociais, a fim de concebê-las como atividades estatais destinadas a instituir órgãos, entidades, bens e serviços que concretamente proporcionem aos seus beneficiários, "mediante a compensação das desigualdades sociais, o exercício de uma liberdade e igualdade real e efetiva" (SARLET, 2009, p. 199).

A Assembleia Constituinte que elaborou a Carta Magna de 1988 se inspirou fortemente em diplomas constitucionais produzidos em contextos histórico-políticos semelhantes ao que então vivia nosso país, isto é, de ruptura com regimes autoritários e de retomada da democracia, citando-se como exemplos os de Portugal, pós-Revolução dos Cravos, e Espanha, em seguida à queda da ditadura de Franco (STRECK, 2002).

A atual Constituição trouxe em seu art. $1^{\circ}$. a menção ao conceito de Estado Democrático de Direito, atribuindo expressamente à República Federativa do Brasil tal qualidade. Ademais, na esteira dos paradigmas inspiradores, elencou em seu bojo invulgar número de direitos a prestações, dotados destarte de fundamentalidade formal e material (SARLET, 2009).

Não obstante a positivação desses direitos prestacionais e a declarada vontade constitucional de sua efetivação, aferível pela própria existência de instrumentos jurídicos como o mandado de injunção (art. $5^{\circ}$., inciso LXXI, da CF), a arguição de descumprimento de preceito fundamental (art. 102, $\S 1^{\circ}$., da CF) e a ação direta de inconstitucionalidade por omissão (art. 103, $\S 2^{\circ}$., da CF), voltados a fazer cessar um estado de violação da Lei Maior, in casu oriundo do non facere estatal (lato sensu) legislativo ou executivo, é notoriamente conhecido o déficit de cumprimento, em especial no que concerne aos direitos a prestações em sentido estrito ou, resumidamente, direitos sociais.

Tal qual se afirmou alhures, os direitos sociais usualmente exigem, para seu concreto gozo, a implementação de políticas públicas sociais. Estas, contudo, sob os mais variados argumentos e escusas, têm sido sistematicamente olvidadas ou recusadas pelos poderes públicos das esferas da Federação, o que conduz à indagação primordial cuja resposta será buscada nas próximas seções deste artigo: de que forma se pode conseguir uma célere e eficaz reversão do quadro omissivo ora descrito? 


\section{O COMPROMISSO DE AJUSTAMENTO DE CONDUTA NO ORDENA- MENTO JURÍDICO BRASILEIRO: NOÇÕES FUNDAMENTAIS}

O compromisso de ajustamento de conduta foi previsto pela primeira vez em nosso ordenamento jurídico no art. 211 do Estatuto da Criança e do Adolescente (Lei n. 8.069/1990), promulgado em 13 de julho de 1990 e publicado no Diário Oficial da União no dia 16 do mesmo mês.

Pouco tempo depois, foi introduzido na Lei da Ação Civil Pública (Lei n. 7.347/1985) pelo art. 113 do Código de Defesa do Consumidor (Lei n. $8.078 / 1990)$, que acrescentou ao art. $5^{\circ}$. daquele diploma o seu $\S 6^{\circ}$., dispondo que os órgãos públicos legitimados à propositura de demandas coletivas poderiam tomar dos interessados compromisso de ajustamento de sua conduta às exigências legais, mediante cominações, que teria a eficácia de título executivo extrajudicial.

Atribuem-se as origens remotas do instituto, por um lado, sob o aspecto fático, à experiência do Ministério Público brasileiro e à sua longa tradição na adoção de práticas de resolução extrajudicial de conflitos de interesses, em especial no âmbito de sua tarefa de atendimento ao público e nas comarcas interioranas, bem como, por outro lado, sob o aspecto normativo, ao art. 55, parágrafo único, da revogada Lei dos Juizados de Pequenas Causas (Lei n. 7.244/1984), que conferia a qualidade de título executivo extrajudicial aos acordos celebrados pelas partes por meio de instrumento escrito referendado pelo Parquet. (MAZZILLI, apud GRINOVER et al., 2007).

Breve e já superada polêmica cercou a introdução do compromisso de ajustamento de conduta na LACP, diante do veto presidencial ao art. $82, \S 3^{\circ}$., do $\mathrm{CDC}$, que trazia previsão idêntica à contida no seu art. 113, regularmente promulgado, conforme noticia Hugo Nigro Mazzilli (2003):

O mesmo Presidente da República que tinha sancionado compromisso de ajustamento no Estatuto da Criança e do Adolescente, pouco depois, vetou o $\S 3^{\circ}$. do art. 82 do Código de Defesa do Consumidor, afirmando agora ser impróprio equiparar um compromisso administrativo a título executivo, ainda mais porque versava apenas prática de conduta e não pagamento de quantia determinada.

Esses argumentos não resistem à análise, porque nada impediria que a lei instituísse, como instituiu, títulos executivos extrajudiciais ainda que de obrigação de fazer. Ademais, o veto foi inócuo, pois, ao mesmo tempo em que se vetava o $\S 3^{\circ}$. do art. 82 do Código de Defesa do Consumidor, e, conquanto dizendo que pelas mesmas razões vetaria idêntica previsão de compromisso de ajustamento, contida no art. 113 do mesmo diploma legal, o chefe do Executivo, por evidente descuido, promulgou na íntegra este último dispositivo, que insti- 
tuiu o compromisso de ajustamento de forma até mais abrangente que o dispositivo do $\S 3^{\circ}$. do art. 82 , este sim efetivamente vetado.

Outrossim, Daniel Roberto Fink, com razão, refuta a possibilidade de veto por extensão do art. 113, afirmando que este restou oficialmente publicado com seu teor intacto e que o veto é ato singular e excepcional, devendo ser interpretado literal e restritivamente no sistema do processo legislativo brasileiro. Logo, o veto de um dispositivo não se estende automaticamente a outro, ainda que de igual conteúdo (FINK, 2001).

Ressalte-se que o compromisso de ajustamento de conduta, além de sua previsão genérica na Lei n. 7.347/1985 e do antecedente no art. 211 do ECA, veio a ser consagrado em outros textos normativos que se seguiram e trataram de matérias específicas atinentes à tutela de interesses transindividuais, merecendo referência a Lei n. 8.884/1994, que cuidou da proteção à ordem econômica e à concorrência, e a Lei n. 9.605/1998, que cuidou da proteção ao meio ambiente, com ênfase aos aspectos administrativos e penais.

A Lei de Improbidade Administrativa (Lei n. 8.429/1992), por sua vez, no art. $17, \S 1^{\circ}$., vedou a possibilidade de transação, acordo ou conciliação no tocante à aplicação de suas sanções aos agentes públicos ímprobos.

Não há consenso doutrinário acerca da natureza jurídica do compromisso de ajustamento de conduta.

Daniel Roberto Fink sustenta o caráter transacional do instituto, cabendo enfatizar que sua análise se restringe aos compromissos que objetivem compor conflitos de interesses metaindividuais oriundos de relações de consumo. Com efeito, assevera o mestre que, versando sobre condições de modo, tempo e lugar do cumprimento de obrigações do fornecedor que tenham por fim extinguir as pendências com os consumidores, sua natureza seria indubitavelmente de compromisso de transação (Id. Ibid.).

Emerson Garcia, ao seu turno, preleciona que o compromisso de ajustamento de conduta ostentaria feição híbrida, atuando como mero ato de reconhecimento de uma obrigação preexistente no tocante ao direito material, visto que indisponível pelos legitimados à sua celebração, e consubstanciando verdadeira transação no que se refere aos aspectos periféricos (GARCIA, 2008).

Hugo Nigro Mazzilli nega o caráter contratual e transacional do instituto, baseando-se na falta de poder de disposição por parte dos órgãos públicos autorizados a tomá-lo, e assevera que o compromisso de ajustamento de conduta seria antes um ato administrativo negocial, ou negócio jurídico de direito público, que consubstancia uma declaração de vontade do poder público (tomador) em sentido coincidente com a do causador efetivo ou potencial do dano (compromissário), que concorda em adequar seu comportamento às exigências legais, MAZZILLI, apud GRINOVER et al., 2007). 
Geisa de Assis Rodrigues discrepa parcialmente do entendimento acima consignado e postula ser o compromisso de ajustamento de conduta um negócio jurídico bilateral da Administração, e não um negócio jurídico administrativo, posto que, ao celebrá-lo, aquela não estaria em posição de superioridade em relação ao administrado. Tratar-se-ia de um pacto, uma solução conciliada, que também teria natureza de equivalente jurisdicional, por consistir em um meio alternativo de composição de conflitos (RODRIGUES, 2010).

Diogo de Figueiredo Moreira Neto (2005) e Marcos Juruena Villela Souto (2010) concebem o instituto como uma espécie de acordo substitutivo, cuja definição é dada com maestria pelo primeiro:

O acordo substitutivo, instituto característico da administração pública consensual, é um ato jurídico complexo praticado entre Administração e administrado ou mesmo com outro ente público, neste caso quando esteja em situação assemelhada à do administrado, com o objetivo de substituir, em determinada relação administrativa, uma conduta primariamente exigível por outra conduta secundariamente negociável, com a finalidade de possibilitar um melhor atendimento de interesses públicos. A Administração flexibiliza, desse modo, sua atuação imperativa, que lhe é própria e lhe serve de modo geral de atuação, adotando uma atuação consensual, que lhe é aberta em hipóteses legais para servir-lhe de modo especial de atuação, sempre que for motivadamente possível demonstrar, que o interesse público primário a seu cargo possa ser atendido mais eficientemente ou mais celeremente, bem como sem infligir prejuízo a outros interesses juridicamente protegidos, que possam ser igualmente ponderados em uma relação conflituosa ou pré-conflituosa que se estabeleça (MOREIRA NETO, 2005, p. 193).

A pluralidade de posicionamentos apresentada permite concluir que o compromisso de ajustamento de conduta é instituto jurídico complexo, refletindo a própria complexidade ínsita no vigente modelo de sociedade pós-industrial, marcado por grandes contradições, pela praticamente irrestrita circulação mundial das informações e do capital e pelos conflitos de massa. Outrossim, as visões dos autores citados devem ser compreendidas por meio dos ângulos pelos quais abordaram a questão. Com efeito, não seria descabido afirmar que, a depender do específico interesse supraindividual objeto do compromisso, uma ou outra será mais correta. Assim, quanto mais próximo do conceito de interesse público primário e mais intensa a tutela estatal sobre ele, o que se dá notadamente com os interesses difusos, maior a adequação das concepções extraídas a partir do Direito Administrativo. Ao revés, quanto mais próximo dos interesses disponíveis de grupos, classes ou indivíduos, o que ocorre com boa parcela dos interesses 
coletivos e dos individuais homogêneos, sobrelevará a pertinência das concepções transacionais. Por óbvio, sempre remanescerá uma grande zona cinzenta, que demandará análise casuística.

Tecidas tais considerações, e desde logo renunciada a pretensão de estabelecer uma ideia definitiva e acabada, é possível conceituar o compromisso de ajustamento de conduta a partir de linhas gerais, com base nas categorias fornecidas pela Teoria Geral do Direito, como um negócio jurídico bilateral e solene, com conteúdos declaratório e constitutivo e eficácia de título executivo extrajudicial, que tem por finalidade prevenir ou solucionar consensualmente conflitos de interesses transindividuais.

Desse conceito sintético podem ser retiradas suas características essenciais.

Trata-se de negócio jurídico, compreendido como manifestação de vontade destinada à produção de efeitos jurídicos queridos pelos agentes e amparados pelo sistema normativo. (PEREIRA, 1997). Outrossim, pode ser classificado como bilateral, visto que, para se aperfeiçoar, necessita da correspondência de duas ou mais vontades (REALE, 1996).

Cabe enfatizar que, de acordo com o entendimento majoritário da doutrina sobre o art. $5^{\circ}$, $\S 6^{\circ}$., da Lei n. 7.347/1985 (FINK, 2001; MAZZILLI, 2001), como tomador, no polo ativo do negócio jurídico, há que figurar, necessariamente, um órgão público ou uma pessoa jurídica de direito público legitimado à propositura da ação civil pública, nos moldes do art. $5^{\circ}$., caput, da LACP, combinado com o art. 82, caput, do Código de Defesa do Consumidor, ao passo que, na condição de compromissário, no seu polo passivo, pode estar presente uma pessoa física ou jurídica, de direito privado ou de direito público, ou mesmo um ente despersonalizado (v.g., espólio ou, eventualmente, até um órgão público independente).

Duas observações merecem ser consignadas.

Primeiramente, é inquestionável a constitucionalidade da previsão legal, no que concerne à atribuição de poder ao Ministério Público para celebrar o compromisso de ajustamento de conduta. Note-se que o art. 129, inciso IX, da Lei Maior estabelece que ao Parquet é lícito exercer outras funções que lhe forem cometidas pela legislação infraconstitucional, desde que compatíveis com sua finalidade institucional. Outrossim, o já citado art. $5^{\circ}$., $\S 6^{\circ}$., da LACP guarda total pertinência com as incumbências do Parquet elencadas no art. 129, incisos II e III, da CF, quais sejam, zelar pelo efetivo respeito dos poderes públicos e dos serviços de relevância pública aos direitos nela assegurados, promovendo as medidas necessárias à sua garantia, e promover o inquérito civil e a ação civil pública, para a proteção do patrimônio público e social, do meio ambiente e de outros interesses difusos e coletivos. Trata-se de ferramenta que confere à Instituição 
uma verdadeira opção estratégica no desempenho de seus misteres, abrindo-lhe portanto certa margem de discricionariedade na escolha de seus mecanismos e formas de atuação.

Em segundo lugar, também não há dúvida de que pessoas jurídicas de direito público e mesmo órgãos públicos independentes (por exemplo, uma Câmara de Vereadores ou Assembleia Legislativa, no trato de assuntos de sua exclusiva alçada) possam ocupar o polo passivo do compromisso de ajustamento de conduta. Inexiste qualquer óbice jurídico para que a União, os Estados, o Distrito Federal e os Municípios, ou seus Poderes e órgãos independentes, assumam obrigações no âmbito de suas respectivas competências constitucionais. Por conseguinte, nada impede que se vinculem, por meio daquele instrumento, à execução de determinadas atividades, tais como a implementação de políticas públicas sob suas responsabilidades (RODRIGUES, apud CHAVES et. al., 2010).

O compromisso de ajustamento de conduta é ainda um negócio jurídico solene, porquanto deve adotar a forma escrita, isto é, há que ser tomado por termo (MAZZILLI, apud GRINOVER et. al., 2007), contendo todas as cláusulas avençadas. Faz-se imprescindível, na sua redação, a descrição minuciosa e objetiva dos obrigados e das obrigações principais e acessórias pactuadas, abrangendo, dentre outros elementos, o tempo e o modo de cumprimento delas, os órgãos e critérios de fiscalização e eventuais estudos ou projetos anexos (GAVRONSKI, 2005; RODRIGUES, apud. CHAVES, ALVES, ROSENVALD, 20010). Por derradeiro, embora sejam recomendáveis, dispensa as assinaturas de testemunhas instrumentárias (MAZZILLI, 2001; RODRIGUES, apud. CHAVES, ALVES, ROSENVALD, 2010), bastando que traga as firmas do presentante legal do órgão público ou da pessoa jurídica que o tomou e da(s) pessoa(s) física(s) ou dos presentantes ou representantes da(s) pessoa(s) jurídica(s) compromissária(s).

Impende frisar que o compromisso de ajustamento de conduta tomado pelo Parquet, segundo o posicionamento mais acertado, não tem o início de sua eficácia condicionado à homologação pelo Conselho Superior do Ministério Público (no caso dos Ministérios Públicos Estaduais) ou pelas Câmaras de Coordenação e Revisão (no caso dos ramos do Ministério Público da União), salvo se assim restar expressamente acordado (MAZZILLI, 2001). Significa que está apto a gerar efeitos desde sua celebração ou de outro momento indicado como termo a quo.Com efeito, o que está sujeito àqueles Órgãos Superiores da Instituição é a eventual promoção de arquivamento de inquérito civil ou de outras peças informativas ensejada pela celebração do pacto (MAZZILLI, 2003). Outrossim, não se olvide que os compromissos tomados pelos demais legitimados não exigem ratificação superior, fazendo com que imposição nesse sentido apenas em relação ao Ministério Público se mostre incongruente e assimétrica, mormente em vista das maiores prerrogativas e garantias de que constitucionalmente desfruta. 
Conforme se exarou anteriormente, o compromisso de ajustamento de conduta tem conteúdos declaratório, consistente na declaração e no reconhecimento da existência de deveres previstos no ordenamento jurídico para o sujeito passivo, e constitutivo, consistente na fixação concreta das obrigações principais e acessórias necessárias para satisfazer aqueles deveres, e, em contrapartida, das condições e limites estabelecidos para a atuação administrativa do tomador no caso concreto.

Os objetos das obrigações assumidas pelo compromissário poderão versar prestações de fazer, não fazer ou dar, tal qual inclusive admite a Resolução n. 23/2007 do Conselho Nacional do Ministério Público, ao preconizar em seu art. 14 o cabimento de avença que vise "à reparação do dano, à adequação da conduta às exigências legais ou normativas e, ainda, à compensação e/ou à indenização pelos danos que não possam ser recuperados."

Daniel Roberto Fink entende que as cominações estabelecidas como obrigações acessórias para a garantia do cumprimento dos deveres pactuados têm natureza de cláusulas penais, podendo ser tanto moratórias quanto compensatórias, para o reforço de obrigações específicas, e sustenta que, na hipótese de inadimplemento, poderão se exigir conjuntamente a cláusula penal e a obrigação principal (FINK, 2001; MAZZILLI, 2001).

Hugo Nigro Mazzilli (2007) e Luciana Aboim Machado Gonçalves da Silva (2004), ao contrário, veem em ditas cominações a natureza de astreintes, que representariam coação de caráter econômico para influir no ânimo do devedor, a fim de que cumpra a obrigação.

A distinção se mostra de grande relevância prática, posto que, tratando-se de astreintes, as cominações podem superar o valor da obrigação principal, o que não ocorre com a cláusula penal, por força do art. 412 do Código Civil.

Parece-nos que a segunda opinião se encontra em maior sintonia com o sistema de tutela coletiva disciplinado pela Lei da Ação Civil Pública e pelo Código de Defesa do Consumidor, notadamente porque, tratando-se de interesses supraindividuais, muitas vezes o conteúdo econômico não será passível de aferição e o cumprimento da obrigação se mostrará inafastável para a sua preservação. É o que se dá, por exemplo, com o meio ambiente. Ademais, nada impede que as astreintes sejam cumuladas com cláusulas penais compensatórias destinadas a assegurar ainda mais intensamente algumas obrigações específicas.

Finalmente, sendo o pacto firmado com órgão público ou pessoa jurídica de direito público, é possível que preveja obrigações e cominações para as próprias autoridades administrativas (RODRIGUES, apud CHAVES, ALVES, ROSENVALD, 2010).

O compromisso de ajustamento de conduta, por expressa determinação legal, tem eficácia de título executivo extrajudicial, dispensando o tomador, no 
caso de descumprimento das obrigações pelo compromissário, de percorrer toda a fase cognitiva do processo judicial. Com efeito, salta-se essa etapa e se obtém a imediata execução da obrigação de fazer, não fazer ou dar consubstanciada no termo.

Nada obsta que as partes aquiesçam na submissão do compromisso à homologação por juízo competente, o que lhe conferirá a eficácia de título executivo judicial e o sujeitará ao regime do cumprimento de sentença instituído no Código de Processo Civil a partir da alteração promovida pela Lei n. 11.232/2005 (MAZZILLI, apud, GRINOVER, MENDES, WATANABE, 2007). Por conseguinte, mais restritas serão as objeções e exceções invocáveis pelo compromissário inadimplente para evitar a invasão de sua esfera jurídica (RODRIGUES, apud CHAVES, ALVES, ROSENVALD, 2010).

O compromisso de ajustamento de conduta tem por escopo prevenir ou solucionar consensualmente conflitos de interesses transindividuais, representando assim uma garantia mínima em prol da coletividade. Portanto, faz-se totalmente viável a celebração de outro mais abrangente por qualquer colegitimado a tomá-lo ou mesmo a propositura de demandas individuais ou coletivas objetivando invalidá-lo ou suplementá-lo (MAZZILLI, apud GRINOVER, MENDES, WATANABE, 2007).

De acordo com Geisa de Assis Rodrigues, havendo o questionamento judicial do pacto por terceiros, será formado litisconsórcio passivo necessário e unitário entre o tomador e o compromissário. Em acréscimo, alude a autora, trazendo em abono de seu posicionamento vários precedentes, que no caso de compromisso celebrado pelo Ministério Público, que não tem personalidade jurídica própria, deverá ser chamado ao processo o ente federativo a que se vincula.

Analisadas as características essenciais do compromisso de ajustamento de conduta, é possível seguir à avaliação de suas vantagens práticas para a implementação de políticas públicas em prol dos direitos fundamentais sociais, no cotejo com o tradicional modelo de judicialização.

\section{AS VANTAGENS DO COMPROMISSO DE AJUSTAMENTO DE CON- DUTA PARA A IMPLEMENTAÇÃO DE POLÍTICAS PÚBLICAS}

O compromisso de ajustamento de conduta envolve a substituição do enfrentamento e da litigância pela via do diálogo, da negociação e do consenso. Alexandre Amaral Gavronski ${ }^{2}$ sustenta que

${ }^{2}$ GAVRONSKI, Alexandre Amaral. Manual de atuação em tutela coletiva para o Ministério Público Federal:parte I - visão geral e atuação extrajudicial. [S.1.]: Ministério Público Federal, 2005. Disponível em: <http://www.prsp.mpf.gov.br/prdc/area-de-atuacao/direitos-humanos/arquivos/Manual_Atuacao_Tutela_Coletiva_MPF.pdf>.Acesso em: 9 nov. 2010.p. 90. 
Se o consenso é a melhor solução para uma crise, como é correntemente afirmado, o compromisso de ajustamento de conduta é o melhor dos instrumentos de atuação do Ministério Público para a solução efetiva dos problemas relacionados à falta de efetividade ou à afronta aos interesses coletivos.

Com efeito, o compromisso de ajustamento de conduta, em relação ao tradicional modelo de judicialização, ostenta grandes e nítidas vantagens, mormente no que concerne à implementação de políticas públicas em prol da concretização de direitos fundamentais sociais. Sem nenhuma pretensão de apresentar rol exaustivo, podemos identificar as principais apontadas pelos estudiosos e sistematizá-las em três grupos: quanto à eficácia preventiva, quanto à otimização dos meios e quanto aos resultados.

De início, há que se reconhecer que o instituto é um valioso mecanismo de tutela jurídica preventiva ${ }^{3}$, podendo operar tanto no plano normativo quanto no fático-concreto.

Argumenta Gregório Assagra de Almeida ${ }^{4}$ que

A tutela jurídica preventiva é a mais genuína forma de proteção jurídica no contexto do Estado Democrático de Direito. Ela decorre do princípio da prevenção geral como diretriz, inserida no princípio democrático (art. $1^{\circ}$. da $\mathrm{CF} / 88$ ).

Por intermédio da tutela jurídica preventiva poderá ser atacado, em uma das suas dimensões, diretamente o ilícito, evitando-se a sua prática, continuidade ou repetição. Com isso, evita-se o dano, que é objeto da tutela jurídica repressiva, mais precisamente a ressarcitória.

Ocorre que muitos danos, especialmente os de dimensão social (aqueles que afetam o ambiente; a saúde do consumidor; a criança e o adolescente; o idoso; a saúde pública etc.), não são possíveis de reparação in natura. Portanto, só restaria nesses casos uma tutela repressiva do tipo compensatória ou do tipo punitiva, que é espécie de tutela jurídica apequenada, já que não responde ao direito, a uma tutela jurídica

${ }^{3}$ GAVRONSKI, Alexandre Amaral. Manual de atuação em tutela coletiva para o Ministério Público Federal:parte I - visão geral e atuação extrajudicial. [S.1.]: Ministério Público Federal, 2005. Disponível em: $<$ http://www.prsp.mpf.gov.br/prdc/area-de-atuacao/direitos-humanos/arquivos/Manual Atuacao_Tutela_Coletiva_MPF.pdf $>$. Acesso em: 9 nov. 2010.p. 90; RODRIGUES, Geisa de Assis. Reflexões sobre a atuação extrajudicial do Ministério Público: inquérito civil público, compromisso de ajustamento de conduta e recomendação legal. In: CHAVES, Cristiano; ALVES, Leonado Barreto Moreira; ROSENVALD, Nelson (Coord.). Temas atuais do Ministério Público: a atuação do Parquet nos 20 anos da Constituição Federal. 2. ed. Rio de Janeiro: Lumen Juris, 2010. p. 197.

${ }^{4}$ ALMEIDA, Gregório Assagra de. O Ministério Público no neoconstitucionalismo: perfil constitucional e alguns fatores de ampliação de sua legitimação social. In: CHAVES, Cristiano; ALVES, Leonado Barreto Moreira; ROSENVALD, Nelson (Coord.). Temas atuais do Ministério Público: a atuação do Parquet nos 20 anos da Constituição Federal. 2. ed. Rio de Janeiro: Lumen Juris, 2010. p. 37.

Rev. Ciênc. Juríd. Soc. UNIPAR, v. 17, n. 2, p. 205-226, jul./dez. 2014 
genuinamente adequada, na sua condição de garantia fundamental do Estado Democrático de Direito (1 ${ }^{\circ}$., $3^{\circ}$. e art. $5^{\circ}$., XXXV, da CF/88).

Nessa linha de prevenção no plano normativo, é pertinente ressaltar que o compromisso de ajustamento de conduta se mostra um exímio instrumento para possibilitar o controle extrajurisdicional de constitucionalidade das leis e dos atos normativos ${ }^{5}$, tanto para coibir a inconstitucionalidade por ação quanto a por omissão, visto que por meio dele se pode impor consensualmente aos Poderes competentes a obrigação de vetar, revogar ou alterar textos que se encontrem em dissonância com as regras e princípios insculpidos na Constituição Federal e nas Constituições Estaduais, bem como a de editar aqueles eventualmente exigidos por tais diplomas e ainda inexistentes.

Também se mostra possível, por meio do instituto, obter o comprometimento dos Poderes competentes no sentido de modificar leis ou atos normativos que, embora guardem compatibilidade vertical com a CF e as CEs, sejam tímidos ou insuficientes aos fins a que se destinam, necessitando de aperfeiçoamentos para melhor atingi-los.

Observe-se a importância de tais medidas nas hipóteses em que as políticas públicas efetivadoras de direitos fundamentais dependerem da existência de legislação infraconstitucional disciplinadora. Vale citar como exemplo o art. 203, inciso $\mathrm{V}$, da Lei Maior, que prevê a garantia de um salário mínimo de benefício mensal à pessoa portadora de deficiência e ao idoso que comprovem não possuir meios de prover à própria manutenção ou de tê-la provida por sua família, conforme dispuser a lei. O dispositivo é complementado pela Lei n. 8.742/1993, que em seus artigos 20 e 21 estabelece os critérios para a fruição do denominado benefício de prestação continuada.

No foco preventivo também deve ser incluída a aptidão do compromisso de ajustamento de conduta para equacionar situações em que interesses transindividuais estejam sendo desatendidos ou violados, sem que se possa identificar exatamente qual o comportamento contrário à lei ou, mais especificamente, quais as causas e as responsabilidades desse desatendimento ${ }^{6}$, assim como para conciliar interesses colidentes e igualmente legítimos. Apenas para exemplificar, é possível imaginar a não rara hipótese de um ente político que, premido por

\footnotetext{
${ }^{5}$ ALMEIDA, Gregório Assagra de. O Ministério Público no neoconstitucionalismo: perfil constitucional e alguns fatores de ampliação de sua legitimação social. In: CHAVES, Cristiano; ALVES, Leonado Barreto Moreira; ROSENVALD, Nelson (Coord.). Temas atuais do Ministério Público: a atuação do Parquet nos 20 anos da Constituição Federal. 2. ed. Rio de Janeiro: Lumen Juris, 2010. p. 49. ${ }^{6}$ GAVRONSKI, Alexandre Amaral. Manual de atuação em tutela coletiva para o Ministério Público Federal:parte I - visão geral e atuação extrajudicial. [S.1.]: Ministério Público Federal, 2005. Disponível em: <http://www.prsp.mpf.gov.br/prdc/area-de-atuacao/direitos-humanos/arquivos/Manual_Atuacao_Tutela_Coletiva_MPF.pdf>.Acesso em: 9 nov. 2010.p. 94.
} 
limitações financeiras, deva optar entre duas políticas públicas que concretizem dois diferentes direitos fundamentais sociais de similar relevância. Ocorrerá nítido conflito que poderá ser composto com vistas ao menor sacrifício de ambos.

Nesse prisma, leciona Geisa de Assis Rodrigues que as autoridades públicas podem se obrigar a realizar atos discricionários no compromisso, uma vez que, como se trata de instituto tipicamente conciliatório, servirá de sede para o exercício do juízo de oportunidade e conveniência. Adverte a jurista que em tal tipo de avença deve haver menção à previsão orçamentária dos gastos para o cumprimento das obrigações ou, ao menos, cláusula que imponha a necessidade de constar em futura proposta orçamentária. ${ }^{7}$

Verifica-se, destarte, que o compromisso de ajustamento de conduta, na faceta de prevenção, ainda favorece o planejamento estratégico e a fixação de prioridades, metas e indicadores pelos poderes públicos para o desempenho de suas atividades e a consecução de seus encargos, induzindo a uma verdadeira parceria e à definição de uma agenda comum na concretização de direitos fundamentais sociais.

Por fim, o pacto permite que a discussão seja levada a horizonte mais amplo que o da ilicitude motivadora da negociação, ajustando-se outros comportamentos do interessado além daquele que ensejou a sua celebração, e também permite que, em acréscimo à correção da conduta constatada como indevida, sejam adotados mecanismos eficazes na repressão ou prevenção de ações ou omissões futuras. ${ }^{8}$

Como se percebe, a eficácia preventiva, em todas essas nuances, é ausente, ou no mínimo bastante mitigada, no modelo de judicialização.

Sob a perspectiva da otimização dos meios, o primeiro aspecto a ser destacado é a maior celeridade que o instituto proporciona para a tutela dos interesses supraindividuais e, in casu, a efetivação de políticas públicas.

É sabido o quadro crítico em que se encontra o Poder Judiciário brasileiro, desprovido de suficientes recursos materiais e humanos e de adequados mecanismos de gestão e abarrotado de feitos para serem julgados.

Por outro lado, a complexidade da atual legislação processual civil viabiliza o manejo de inúmeros incidentes, recursos e meios impugnativos, favore-

\footnotetext{
${ }^{7}$ RODRIGUES, Geisa de Assis. Reflexões sobre a atuação extrajudicial do Ministério Público: inquérito civil público, compromisso de ajustamento de conduta e recomendação legal. In: CHAVES, Cristiano; ALVES, Leonado Barreto Moreira; ROSENVALD, Nelson (Coord.). Temas atuais do Ministério Público: a atuação do Parquet nos 20 anos da Constituição Federal. 2. ed. Rio de Janeiro: Lumen Juris, 2010. p. 202.

${ }^{8}$ GAVRONSKI, Alexandre Amaral. Manual de atuação em tutela coletiva para o Ministério Público Federal:parte I - visão geral e atuação extrajudicial. [S.1.]: Ministério Público Federal, 2005. Disponível em: <http:/www.prsp.mpf.gov.br/prdc/area-de-atuacao/direitos-humanos/arquivos/Manual_Atuacao_Tutela_Coletiva_MPF.pdf >.Acesso em: 9 nov. 2010.p. 90.
} 
cendo as manobras protelatórias e a "eternização" de demandas judiciais.

Os fatores apontados, somados, contribuem decisivamente para a morosidade do aparato judicial e o seu consequente descrédito perante grande parcela da sociedade.

As decorrências da lentidão das instâncias formais de Justiça se tornam dramáticas para a proteção dos interesses metaindividuais, cuja relevância estimulou a criação de instrumento mais expedito que o transcurso do processo. ${ }^{9}$

O compromisso de ajustamento de conduta tende a solucionar de forma mais rápida e efetiva a irregularidade, visto que pressupõe, em princípio, boa vontade para cumprimento espontâneo da obrigação assumida por parte daquele que está em situação irregular, assim como prevê sanções líquidas e certas para o descumprimento, exigíveis desde logo, quais sejam, as multas. Note-se que, nas ações civis públicas ou coletivas, as astreintes cominadas liminarmente, embora devidas desde o dia em que se houver caracterizado o inadimplemento, somente serão exigíveis do réu após o trânsito em julgado da decisão favorável ao autor, nos termos do art. $12, \S 2^{\circ}$., da Lei n. $7.347 / 1985 .^{10}$

Outro ponto a ser enfatizado é que, conquanto as atividades inerentes à celebração do compromisso sejam patrocinadas por verbas públicas, são menos onerosas que a movimentação da máquina jurisdicional, visto que, primeiramente, evitam o ingresso no Poder Judiciário e as despesas daí decorrentes; em segundo lugar, não há especial dispêndio para os órgãos ou entes públicos tomadores, posto que as atividades investigatórias das lesões ou ameaças aos interesses transindividuais ocorrem e são custeadas com ou sem o posterior advento do pacto; e, por último, pode-se conseguir do obrigado o ressarcimento dos gastos a que deu causa com o seu comportamento transgressor da ordem jurídica. ${ }^{11}$

Finalmente, não se pode olvidar a possibilidade de serem estabelecidas obrigações que recaiam diretamente sobre as autoridades administrativas dos órgãos ou entes públicos compromissários, como modo de reforçar a garantia de

\footnotetext{
${ }^{9}$ RODRIGUES, Geisa de Assis. Reflexões sobre a atuação extrajudicial do Ministério Público: inquérito civil público, compromisso de ajustamento de conduta e recomendação legal. In: CHAVES, Cristiano; ALVES, Leonado Barreto Moreira; ROSENVALD, Nelson (Coord.). Temas atuais do Ministério Público: a atuação do Parquet nos 20 anos da Constituição Federal. 2. ed. Rio de Janeiro: Lumen Juris, 2010. p. 197.

${ }^{10}$ GAVRONSKI, Alexandre Amaral. Manual de atuação em tutela coletiva para o Ministério Público Federal:parte I - visão geral e atuação extrajudicial. [S.1.]: Ministério Público Federal, 2005. Disponível em: <http://www.prsp.mpf.gov.br/prdc/area-de-atuacao/direitos-humanos/arquivos/Manual_Atuacao_Tutela_Coletiva_MPF.pdf $>$. Acesso em: 9 nov.2010.p. 90.

${ }^{11}$ RODRIGUES, Geisa de Assis. Reflexões sobre a atuação extrajudicial do Ministério Público: inquérito civil público, compromisso de ajustamento de conduta e recomendação legal. In: CHAVES, Cristiano; ALVES, Leonado Barreto Moreira; ROSENVALD, Nelson (Coord.). Temas atuais do Ministério Público: a atuação do Parquet nos 20 anos da Constituição Federal. 2. ed. Rio de Janeiro: Lumen Juris, 2010. p. 197.
} 
escorreito adimplemento das cláusulas avençadas ${ }^{12}$, o que é de capital importância no campo específico da implementação de políticas públicas.

Em suma, quanto à otimização dos meios, o instituto é mais célere e econômico que a opção jurisdicional e tende a oferecer mais garantias ao cumprimento das obrigações assumidas.

Partindo para os resultados, o compromisso de ajustamento de conduta, notadamente por sua feição consensual, que pressupõe mútuo entendimento e assunção voluntária de obrigações, por certo enseja maiores proveitos que os concedidos por uma sentença prolatada em sede de processo judicial contencioso.

Exara Gregório Assagra de Almeida, com razão, que o Poder Judiciário se mostra ainda despreparado para enfrentar demandas que envolvam direitos massificados e questões sociais fundamentais, respondendo mal a elas. ${ }^{13}$

Com efeito, devido a certo conservadorismo, as instâncias judiciais, salvo honrosas exceções, continuam presas a um ultrapassado modelo liberal-individualista-normativista de compreensão e produção/reprodução do Direito, ignorando a revolução paradigmática representada pela ascensão dos interesses supraindividuais. ${ }^{14}$

Algumas circunstâncias tendem a favorecer o emprego do compromisso de ajustamento de conduta em busca de resultados mais satisfatórios e adequados à tutela dos interesses metaindividuais: a) grande complexidade das questões envolvidas, relacionadas a conhecimentos extrajurídicos e muito específicos, e que, por isso, seriam tratadas com muita dificuldade na via judicial, porquanto em regra dependentes de demoradas e plurívocas perícias; b) dificuldade de se visualizar com clareza a forma de corrigir a lesão transindividual ou a existência de discricionariedade nesta identificação; c) presença de vários sujeitos, muitos deles possíveis demandados, com interesses conflitantes e de difícil coordenação em um processo judicial, exigindo exaustivas negociações e concessões mútuas, cujo registro possibilita a execução direta das obrigações pactuadas; e d) dificuldade de garantir o correto cumprimento da lei ou da decisão judicial em virtude da ausência de mecanismos eficazes de fiscalização ou sanção,que podem ser

\footnotetext{
${ }^{12}$ RODRIGUES, Geisa de Assis. Reflexões sobre a atuação extrajudicial do Ministério Público: inquérito civil público, compromisso de ajustamento de conduta e recomendação legal. In: CHAVES, Cristiano; ALVES, Leonado Barreto Moreira; ROSENVALD, Nelson (Coord.). Temas atuais do Ministério Público: a atuação do Parquet nos 20 anos da Constituição Federal. 2. ed. Rio de Janeiro: Lumen Juris, 2010. p. 201.

${ }^{13}$ ALMEIDA, Gregório Assagra de. O Ministério Público no neoconstitucionalismo: perfil constitucional e alguns fatores de ampliação de sua legitimação social. In: CHAVES, Cristiano; ALVES, Leonado Barreto Moreira; ROSENVALD, Nelson (Coord.). Temas atuais do Ministério Público: a atuação do Parquet nos 20 anos da Constituição Federal. 2. ed. Rio de Janeiro: Lumen Juris, 2010. p. 27-28.

${ }^{14}$ STRECK, Lenio Luiz. Jurisdição constitucional e hermenêutica: uma nova crítica do direito. Porto Alegre: Livraria do Advogado, 2002. p. 18.
} 
acordados no compromisso. ${ }^{15}$

Tais circunstâncias invariavelmente são verificadas na implementação de políticas públicas, que necessitam de estudos aprofundados e multidisciplinares de carências e de meios de supri-las, de análise de impactos orçamentários e de relações custo-benefício e de definição de grupos ou classes de pessoas abrangidas, entre outros expedientes.

Cabe recordar que o compromisso de ajustamento de conduta tem a eficácia de título executivo extrajudicial, autorizando desde logo, caso ocorra o inadimplemento, o manejo do processo de execução, no escopo de obter a satisfação das obrigações de fazer, não fazer ou dar pactuadas, nos moldes dos artigos 566 e seguintes do Código de Processo Civil. Frise-se que a Súmula n. 279 do Superior Tribunal de Justiça expressamente admite a execução de título extrajudicial contra a Fazenda Pública, sem efetuar qualquer distinção entre os tipos de prestações que incorpore.

Ademais, havendo a homologação judicial da avença, passará a ter eficácia de título executivo judicial e dará azo ao cumprimento de sentença, na forma dos artigos 461, 461-A ou 475-I e seguintes do Estatuto Instrumental.

Os aludidos meios são plenamente utilizáveis, sem nenhum óbice jurídico, para compelir os poderes públicos ao atendimento dos encargos assumidos no acordo e destinados a efetivar políticas públicas e a concretizar direitos fundamentais sociais.

Constata-se, pois, que o compromisso de ajustamento de conduta se mostra superior ao modelo de judicialização também na ótica dos resultados possíveis.

Encerrando, deve-se enfatizar que a prevenção e a resolução consensual de controvérsias por meio do instituto, em especial no tocante à implementação de políticas públicas, trazem um plus democrático, pois se originam do diálogo e do mútuo entendimento e denotam o comprometimento das esferas estatais com a concretização dos direitos fundamentais sociais, assim como, por óbvio, visto serem extrajudiciais, afastam os questionamentos e as críticas que pairam sobre a expansão da jurisdição constitucional e a judicialização da política. ${ }^{16}$

\footnotetext{
${ }^{15}$ GAVRONSKI, Alexandre Amaral. Manual de atuação em tutela coletiva para o Ministério Público Federal:parte I - visão geral e atuação extrajudicial. [S.1.]: Ministério Público Federal, 2005. Disponível em: <http://www.prsp.mpf.gov.br/prdc/area-de-atuacao/direitos-humanos/arquivos/Manual_Atuacao_Tutela_Coletiva_MPF.pdf $>$. Acesso em: 9 nov. 2010. p. 93-94.

${ }^{16}$ Sobre tais questionamentos e críticas, consulte-se, por todos, LIMA, Thadeu Augimeri de Goes. Tutela constitucional do acesso à justiça. Porto Alegre: Núria Fabris, 2013. p. 56-73, trazendo várias referências bibliográficas.
} 


\section{CONSIDERAÇÕES FINAIS}

Sopesados os argumentos encontrados na análise do compromisso de ajustamento de conduta e tecidas as pertinentes comparações com o tradicional modelo de judicialização, vê-se que a hipótese lançada no início do trabalho resta confirmada. $\mathrm{O}$ instituto realmente se mostra um eficaz instrumento para a implementação de políticas públicas e a concretização de direitos fundamentais sociais.

A intensificação de seu uso, outrossim, envolve o desenvolvimento de competências negociais e de gestão por parte dos agentes dos órgãos e entes públicos legitimados a tomá-lo, que necessariamente devem se somar às competências técnico-jurídicas que notadamente já possuem.

Não se olvide, ainda, que dentro desses órgãos e entes também se fazem imprescindíveis o reforço da formação interdisciplinar e o investimento no apoio técnico de especialistas de outras áreas, para melhor dar conta das peculiaridades que cada interesse transindividual ostenta, mormente os complexos fatores inerentes às políticas públicas.

Bem subsidiado e manejado, portanto, o compromisso de ajustamento de conduta se mostra um excelente mecanismo para o resgate das promessas emancipatórias trazidas na Lei Maior.

\section{REFERÊNCIAS}

ALMEIDA, G. A. de. O Ministério Público no neoconstitucionalismo: perfil constitucional e alguns fatores de ampliação de sua legitimação social. In: CHAVES, Cristiano; ALVES, Leonado Barreto Moreira; ROSENVALD, Nelson (Coord.). Temas atuais do Ministério Público: a atuação do Parquet nos 20 anos da Constituição Federal. 2. ed. Rio de Janeiro: Lumen Juris, 2010. p. 17-60.

CAMBI, E. Neoconstitucionalismo e neoprocessualismo: direitos fundamentais, políticas públicas e protagonismo judiciário. São Paulo: Revista dos Tribunais, 2009.

DALLARI, D. de A. A constituição na vida dos povos: da idade média ao século XXI. São Paulo: Saraiva, 2010.

FARIA, J. E. O direito na economia globalizada. São Paulo: Malheiros, 2004.

FINK, D. R. Compromisso de ajustamento de conduta. In: GRINOVER, Ada 
Pellegrini et al. Código de defesa do consumidor: comentado pelos autores do anteprojeto. 7. ed. Rio de Janeiro: Forense Universitária, 2001. p. 893-906.

GARCIA, E. Ministério Público: organização, atribuições e regime jurídico. 3. ed. Rio de Janeiro: Lumen Juris, 2008.

\section{GAVRONSKI, A. A. Manual de atuação em tutela coletiva para o}

Ministério Público Federal: parte I - visão geral e atuação extrajudicial. [S.l.]. Ministério Público Federal, 2005. Disponível em: <http://www.prsp.mpf.gov. br/prdc/area-de-atuacao/direitos-humanos/arquivos/Manual_Atuacao_Tutela_ Coletiva_MPF.pdf>. Acesso em: 9 nov. 2010.

GRAU, R. R. O direito posto e o direito pressuposto. 6. ed. São Paulo: Malheiros, 2005.

LIMA, T. A. de G. Tutela constitucional do acesso à justiça. Porto Alegre: Núria Fabris, 2013.

MAZZILLI, H. N. A defesa dos interesses difusos em juízo. 13. ed. São Paulo: Saraiva, 2001.

. Os interesses transindividuais: sua defesa judicial e extrajudicial. In: MINISTÉRIO DA SAÚDE. Direito sanitário e saúde pública. Brasília, 2003. v. 1.p. 87-112.

. Compromisso de ajustamento de conduta: análise à luz do anteprojeto do código brasileiro de processos coletivos. In: GRINOVER, Ada Pellegrini; MENDES, Aluísio Gonçalves de Castro; WATANABE, Kazuo (Coord.). Direito processual coletivo e o anteprojeto de código brasileiro de processos coletivos. São Paulo: Revista dos Tribunais, 2007. p. 231-243.

MOREIRA NETO, D. de F. Curso de direito administrativo. 14. ed. Rio de Janeiro: Forense, 2005.

PEREIRA, C. M. da S. Instituições de direito civil. 18. ed. Rio de Janeiro: Forense, 1997. v. 1.

REALE, M. Lições preliminares de direito. 23. ed. São Paulo: Saraiva, 1996.

RODRIGUES, G. de A. Reflexões sobre a atuação extrajudicial do Ministério Público: inquérito civil público, compromisso de ajustamento de conduta 
e recomendação legal. In: CHAVES, Cristiano; ALVES, Leonado Barreto Moreira; ROSENVALD, Nelson (Coord.). Temas atuais do Ministério Público: a atuação do Parquet nos 20 anos da Constituição Federal. 2. ed. Rio de Janeiro: Lumen Juris, 2010. p. 175-222.

SARLET, I. W. A eficácia dos direitos fundamentais: uma teoria geral dos direitos fundamentais na perspectiva constitucional. 10. ed. Porto Alegre: Livraria do Advogado, 2009.

SILVA, . A. M. G. da. Termo de ajustamento de conduta. São Paulo: LTr, 2004.

SILVA, V. A. da. Direitos fundamentais: conteúdo essencial, restrições e eficácia. 2. ed. São Paulo: Malheiros, 2010.

SOUTO, M. J. V. A era da consensualidade e o Ministério Público. In: RIBEIRO, Carlos Vinícius Alves (Org.). Ministério Público: reflexões sobre princípios e funções institucionais. São Paulo: Atlas, 2010. p. 286-304.

STRECK, L. L. Jurisdição constitucional e hermenêutica: uma nova crítica do direito. Porto Alegre: Livraria do Advogado, 2002.

\title{
CONDUCT ADJUSTMENT COMMITMENT AND THE IMPLEMENTATION OF PUBLIC POLICIES
}

\begin{abstract}
This paper studies the effectiveness of the conduct adjustment commitment as a tool that may be used for the implementation of public policies and the enforcement of fundamental social rights. It uses the hypothetical-deductive, the dialectical and the historical-evolutionary methods and starts from the theoretical frameworks inserted in the neo-constitutionalist design. It begins with an approach to the neo-constitutionalism and its manifestation in Brazil, emphasizing that the fundamental social rights provided in the 1988 Federal Constitution suffer an enforcement crisis due to the absence of public social policies capable of implementing them. It continues with the analysis of the conduct adjustment commitment in the Brazilian Law, setting its background, its legal nature and concept, and its essential characteristics, especially the organs authorized to apply it, its object, its form and its effects. Following, it highlights the benefits of the prevention and the extrajudicial settlement of cross-individual conflicts enabled by the conduct adjustment commitment, mostly the greater celerity and efficiency and the deviation of the criticism toward the expansion of the constitu-
\end{abstract}


tional jurisdiction and the judicialization of politics. The conclusion confirms the hypothesis developed in the introduction, verifying the institute's great relevance for the implementation of public policies and the concretization of fundamental social rights. The value and originality of the work are mainly in the analytical comparison of the consensual model with the traditional judicially adjudicated solution and in the contrast to the advantages of the former over the latter.

KEYWORDS: Conduct adjustment commitment; Public policies; Fundamental social rights.

\section{COMPROMISO DE AJUSTE DE CONDUCTA E IMPLEMENTACIÓN DE POLÍTICAS PÚBLICAS}

RESUMEN: El artículo trata sobre la eficacia del compromiso de ajuste de conducta como instrumento para obtener la implementación de políticas públicas y el cumplimiento de derechos sociales fundamentales. Hace uso de los métodos hipotéticos deductivos, dialécticos e histórico evolutivo y parte de marcos teóricos inseridos en la concepción neo constitucionalista. Inicia por el enfoque del neo constitucionalismo y de su manifestación en Brasil, constatando que los derechos fundamentales sociales previstos en la Constitución Federal de 1988 sufren una crisis de efectuación decurrente de la ausencia de políticas públicas sociales capaces de impleméntalos. Continúa con el análisis del compromiso de ajuste de conducta en el Derecho brasileño, fijando sus antecedentes, su naturaleza jurídica, concepto y sus características esenciales, especialmente los órganos autorizados a celebrarlo, su objetivo, su forma y sus efectos. Enseguida, resalta las ventajas de la prevención y de la resolución extrajudicial de los conflictos transindividuales posibilitados por el compromiso de ajuste de conducta, especialmente las mayores celeridad y efectividad y el alejamiento de las críticas dirigidas a la expansión de la jurisdicción constitucional y la judicialización de la política. La conclusión confirma la hipótesis desarrollada en la introducción, verificando la gran relevancia del instituto para la implementación de políticas públicas y la concretización de los derechos fundamentales sociales. El valor y la originalidad del trabajo están, principalmente, en el cotejo analítico del modelo consensual con la tradicional solución adjudicada estatal y en destaque las ventajas del primero sobre el último.

PALABRAS CLAVE: Compromiso de ajuste de conducta; Políticas públicas; Derechos fundamentales sociales. 